\title{
Percutaneous Nephrolithotomy in a Previously Operated Kidney
}

\author{
Adnan Siddiq Awan, Shoaib Mithani, Fakhir Yousuf, Shakeel Haseeb, Waqar Hassan and Suneel Kumar \\ Department of Urology, The Kidney Centre Postgraduate Training Institute, Karachi, Pakistan
}

\begin{abstract}
Objective: To ascertain the safety and efficacy of percutaneous nephrolithomy in patients with previous open renal surgery. Study Design: Descriptive study.

Place and Duration of Study: The Kidney Centre Postgraduate Training Institute, Karachi from January to December 2018.

Methodology: Patients with previous open renal surgery underwent percutaneous nephrolithomy during study period (Group A). Equal number of percutaneous nephrolithomy patients without previous open surgery taken as controls (Group B). Safety was defined in terms of 'blood loss' as change in hemoglobin (HB) level and 'blood transfusion,' while efficacy was defined in terms of 'stone clearance' and were compared between both the groups.

Results: There were a total of 87 patients. Both groups had comparative gender ratio $[p=0.858]$. Mean age $[p=0.132]$ and BMI $[p=0.879]$ of patients in both groups was not significantly different from each other. Both groups showed no statistically significant difference in terms of values of stone size $[p=0.186]$, stone laterality $[p=0.437]$ stone location $[p=0.949]$, preoperative $\mathrm{Hb}[p=0.095]$, postoperative $\mathrm{Hb}[p=0.423$ ] and change in $\mathrm{Hb}$ (indicating blood loss, $p=0.398$ ). Puncture levels were significantly different among both groups (supracostal puncture in 18 and 36 patients; infracostal puncture in 63 and 51 patients in groups $A$ and $B$, respectively, $p=0.006$ ), while operative time $[p=0.787]$, calyx punctured [ $p=0.051]$, double puncture $[p=0.787]$, nephrostomy tube $[p=0.288]$ were statistically not different among groups. Similar number of patients demonstrated residual stones [ $p=0.773$ ], along with residual stone sizes [Group A $(0.5 ; 0.5)$ and Group B $(0.65 ; 0.38)][p=$ $0.445]$. Intra- and postoperative complications like blood transfusion $[p=0.700]$ and fever $[p=1.000]$ along with hospital stay $[p=0.614]$ were comparable among groups.
\end{abstract}

Conclusion: Percutaneous nephrolithomy is safe and effective in previously operated kidneys despite the possibility of calyceal anatomy distortion and scarring.

Key Words: Percutaneous nephrolithotomy, Open surgery, Kidney calculi.

How to cite this article: Awan AS, Mithani S, Yousuf F, Haseeb S, Hassan W, Kumar S. Percutaneous Nephrolithotomy in a Previously Operated Kidney. J Coll Physicians Surg Pak 2020; 30(11):1201-1205.

\section{INTRODUCTION}

Urolithiasis is a highly prevalent disease worldwide with rates ranging from 7 to $13 \%$ in North America, 5-9\% in Europe, and 1-5\% in Asia. ${ }^{1}$ In the current times, percutaneous nephrolithotomy (PCNL) is the gold standard treatment for renal calculi of 2 cms or more. ${ }^{2}$ This revolutionary procedure was pioneered by Fernstrom and Johansson in $1976 .{ }^{3}$ It was further refined and innovated to its role as a gold standard procedure. ${ }^{4,5} \mathrm{PCNL}$ is also indicated in renal stones smaller than $2 \mathrm{cms}$ in cases where the stone is refractory to non-surgical treatment of extracorporeal shockwave lithotripsy or for diverticularstones.

Correspondence to: Dr. Adnan Siddiq Awan, Department of Urology, The Kidney Centre Postgraduate Training Institute, Karachi, Pakistan

E-mail: dradnansiddiq@hotmail.com

Received: October 23, 2019; Revised: February 14, 2020; Accepted: March 09, 2020

DOI: https://doi.org/10.29271/jcpsp.2020.11.1201
PCNL has been deemed surgically difficult in previously operated cases due to scarring and distorted tissue anatomy. ${ }^{6,7}$ Some authors have concluded that PCNL in previously operated kidney has similar safety and efficacy, but there are difficulties in establishing renal access; and it may require multiple attempts. ${ }^{8}$ Failures in procedure also comprised of large residual stones requiring re-procedure in some studies. ${ }^{9}$ Some recent literature also shows that $\mathrm{PCNL}$ is safe and effective even as a secondary procedure after previous open surgery and a primary PCNL; thus ignoring the fear of infundibular stenosis, perinephric fibrosis, bowel displacement, and incisional hernia. ${ }^{10}$ Another rare complication is the presence of vascular malformations / complications during or after PCNL in previously operated kidneys. These vascular events were diagnosed on renal vascularangiographyand ultimately required angioembolisation in a few cases. ${ }^{11}$

The safety of PCNL in previously operated patients has even been demonstrated in pediatric population. ${ }^{12}$ Then again, few authors have emphasised their concerns over procedural struggle due to presence of retro-renal colon in pediatric 
patients, necessitating indication of non-ionic contrastCT scans preoperatively. ${ }^{13}$

The rationale of this study was to provide further input on the safety of PCNL in previously operated patients in order to strengthen the evidence, because the data on previously operated patients undergoing PCNL is scarce nationally; and vastly debatable and contrasting as per international literature. Very few prospective studies have been published internationally with such a variable.

The objective of the study was to ascertain the safety and efficacy of percutaneous nephrolithomy in patients with previous open renal surgery.

\section{METHODOLOGY}

This descriptive study was conducted at The Kidney Centre Postgraduate Training Institute, Karachi, Pakistan. Patients included were those who underwent PCNL from January 2018 till December 2018. Prior to the study, Institutional Ethical Review Board approval was taken (Reference \# 76-URO-052019).

Eighty seven (87) patients with previous history of open renal surgery (pyelolithotomy) underwent PCNL during study period and were placed into Group A. An equal number of PCNL patients who never had previous open renal surgery were taken as controls and comprised the Group B. Controls had similar demographic and investigative parameters as the cases and these values were also recorded for both groups. Both groups underwent PCNL by the same surgeon.

The PCNL procedure performed in both groups was the same. After receiving general anesthesia, cystoscopy was done in dorsal lithotomy position, followed by ureteric catheterization and Foley's catheter placement. Position was changed to prone and renal system was accessed under fluoroscopic guidance. After successful puncture with lumber puncture $18 \mathrm{G}$ needle, guide wire was inserted into the renal system, followed by serial dilatation of the tract with help of Alken's serial metallic dilators. A 30 French Amplatz sheath was placed into the renal system and stones fragmented through the nephroscope using pneumatic lithotripter. Foreign body grasper was used for stone fragments retrieval. Nephrostomy tube was kept at the end of some procedures as per requirement of drainage, to be removed on second postoperative day. First postoperative day hemoglobin levels were compared with preoperative data and recorded on proforma. Similarly, operative parameters like puncture details, number of tracts, operative time, intra- and postoperative complications along with duration of stay were also recorded for both groups. Safety was defined in terms of 'blood loss' as change in hemoglobin (HB) levels after the procedure, and 'blood transfusion' while efficacy was defined in terms of 'stone clearance' and were compared between both groups.

All recorded data underwent normality check through ShapiroWilk test. Data that was normally distributed was described in terms of mean and standard deviation for continuous variables (age, BMI, pre-operative and postoperative $\mathrm{Hb}$ ); and parametric testing by independent t-test was performed. Data that failed normality check (age, stone size, change in $\mathrm{Hb}$, operative time, residual stone size and hospital stay) was described in terms of median and interquartile ratio; and was tested using MannWhitney Utest.

Table I: Baseline demographics and clinical characteristics.

\begin{tabular}{|c|c|c|c|}
\hline & $\begin{array}{c}\text { Group-A } \\
\text { (previously operated) } \\
\text { cases }\end{array}$ & $\begin{array}{c}\text { Group-B } \\
\text { (Non-operated) } \\
\text { controls }\end{array}$ & $\begin{array}{c}\text { p-value } \\
(p)\end{array}$ \\
\hline \multicolumn{4}{|l|}{ Gender } \\
\hline Male (n number) & 66 & 67 & \multirow{2}{*}{$p=0.858$} \\
\hline Female ( $\mathrm{n}$ number) & 21 & 20 & \\
\hline \multicolumn{4}{|l|}{ Age (years) } \\
\hline Median & 45 & 50 & \multirow{2}{*}{$p=0.132$} \\
\hline Interquartile range & 27 & 27 & \\
\hline \multicolumn{4}{|l|}{$\mathrm{BMI}\left(\mathrm{kg} / \mathrm{m}^{2}\right)$} \\
\hline Mean & 24.61 & 24.49 & \multirow{2}{*}{$p=0.879$} \\
\hline Standard deviation & +5.35 & +5.02 & \\
\hline \multicolumn{4}{|l|}{ Stone Size $(\mathrm{cms})$} \\
\hline Median & 2.0 & 2.0 & \multirow{2}{*}{$p=0.186$} \\
\hline Interquartile range & 1.0 & 0.8 & \\
\hline \multicolumn{4}{|l|}{ Stone Side } \\
\hline Right & 57 & 55 & \multirow{2}{*}{$p=0.437$} \\
\hline Left & 30 & 32 & \\
\hline \multicolumn{4}{|l|}{ Stone Location } \\
\hline Upper calyx & 16 & 12 & $p=0.268$ \\
\hline Middle calyx & 28 & 24 & $p=0.310$ \\
\hline Lower calyx & 40 & 36 & $p=0.323$ \\
\hline Pelvis & 26 & 39 & $p=0.030$ \\
\hline
\end{tabular}

Table II: Investigative and operative parameters.

\begin{tabular}{|c|c|c|c|}
\hline & $\begin{array}{c}\text { Group-A } \\
\text { (previously } \\
\text { operated) } \\
\text { cases }\end{array}$ & $\begin{array}{c}\text { Group-B } \\
\text { (non-operated) } \\
\text { controls }\end{array}$ & $\begin{array}{c}\text { p-value } \\
\text { (p) }\end{array}$ \\
\hline \multicolumn{4}{|c|}{ Preoperative hemoglobin (gm/dl) } \\
\hline Mean & 13.31 & 12.56 & \multirow{2}{*}{$p=0.095$} \\
\hline Standard deviation & +1.61 & +1.84 & \\
\hline \multicolumn{4}{|c|}{ Post-operative hemoglobin (gm/dl) } \\
\hline Mean & 11.77 & 11.28 & \multirow{2}{*}{$p=0.423$} \\
\hline Standard deviation & +1.70 & +1.80 & \\
\hline \multicolumn{4}{|l|}{ Change in hemoglobin ( $\mathrm{gm} / \mathrm{dl}$ ) } \\
\hline Median & 1.10 & 1.10 & \multirow{2}{*}{$p=0.398$} \\
\hline Interquartile range & 1.60 & 1.10 & \\
\hline \multicolumn{4}{|l|}{ Operative time (minutes) } \\
\hline Median & 120 & 120 & \multirow{2}{*}{$p=0.787$} \\
\hline Interquartile range & 50 & 50 & \\
\hline \multicolumn{4}{|l|}{ Calyx punctured } \\
\hline Upper calyx & 25 & 38 & \multirow{3}{*}{$p=0.051$} \\
\hline Middle calyx & 08 & 11 & \\
\hline Lower calyx & 54 & 38 & \\
\hline \multicolumn{4}{|l|}{ Puncture level } \\
\hline Supracostal & 18 & 36 & \multirow{2}{*}{$p=0.006$} \\
\hline Infracostal & 63 & 51 & \\
\hline \multicolumn{4}{|l|}{ Double puncture } \\
\hline Number of patients & 08 & 07 & $p=0.787$ \\
\hline \multicolumn{4}{|l|}{ Nephrostomy tube placed } \\
\hline Number of patients & 45 & 38 & $p=0.288$ \\
\hline \multicolumn{4}{|l|}{ Complications } \\
\hline Residual stone & 07 & 06 & $p=0.773$ \\
\hline Residual size (median; IQR) & $0.50 ; 0.50$ & $0.65 ; 0.38$ & $p=0.445$ \\
\hline Blood transfusion & 04 & 03 & $p=0.700$ \\
\hline Fever & 01 & 01 & $p=1.000$ \\
\hline Urosepses & 00 & 00 & --- \\
\hline Pleural effusion & 00 & 00 & --- \\
\hline Conversion to open & 00 & 00 & --- \\
\hline Re-PCNL & 00 & 00 & --- \\
\hline \multicolumn{4}{|l|}{ Hospital stay } \\
\hline Number of days & $3.00 ; 1.00$ & $3.00 ; 1.00$ & $p=0.614$ \\
\hline
\end{tabular}


Categorical variables (gender, stone location and laterality, calyx punctured, level of puncture, nephrostomy tube and complications) were described in terms of ' $n$ number' $\&$ were compared between the 2 groups applying chi square Test. SPSS (Statistical Packages of Social Sciences) version 20 was used to analyze data. P-value of less than 0.05 was taken as statistically significant.

\section{RESULTS}

An approximately equal number of male and female patients underwent $\mathrm{PCNL}$ in both groups $\mathrm{A}$ and $\mathrm{B}[p=0.858]$, as shown in Table I. Median and interquartile ratio of patients in group-A and $B$ was not significantly different from each other $[p=0.132]$ as shown in Table I. Similarly, mean BMI patients in groups A and B was also not significantly different from each other $[p=0.879]$ as shown in Tablel.

When it comes to stone parameters, both groups showed statistically significant values in terms of stone size $[p=0.186]$, stone laterality $[p=0.437]$ and stone location as shown in Table I.

In term of laboratory parameters, values in both groups were not significant different among each other in terms of preop $\mathrm{Hb}$ [ $p=0.095]$, post-op HB $[p=0.423]$ and change in $\mathrm{Hb}$ (blood loss) $[p=0.398]$ as shown in Table II.

Among the operative parameters, puncture level values were significantly different among both groups (supracostal puncture in 18 and 36 patients; infracostal puncture in 63 and 51 patients in group $A$ and $B$ respectively) $[p=0.006]$, while rest of variables like operative time $[p=0.787]$, calyx punctured [ $p=$ $0.051]$, double puncture [ $p=0.787]$, nephrostomy tube $[p=$ 0.288 ] were statistically significant among both groups $A$ and $B$, as shown in Table II. A nearly equal number of patients demonstrated Residual stones in both groups [ $p=0.773$ ], along with statistically significant residual stone size among Groups A and $\mathrm{B}[p=0.445]$ as shown in Table II.

Among both groups, differences in intra- and postoperative complications like blood transfusion $[p=0.700]$ and fever $[p=$ 1.000] were also significantly significance among each other, while there were no cases of known complications like urosepsis, pleural effusion, conversion to open procedure or repeat noted in any of the groups, as shown in Table II. Median and interquartile ratio of hospital stay was also not statistically signicantamong both groups [ $p=0.614]$, as shown in Tablell.

\section{DISCUSSION}

In this study, intra- and postoperative complications like blood transfusion and fever were significantly different between the groups, while there were no cases of known complications like urosepsis and pleural effusion.

Kidney stones present a sizable worldwide health problem. Pakistan is situated in the Afro-Asian stone belt (stretching from Egypt, Middle East, Iran, Pakistan, India, and Thailand up to Indonesia and the Philippines) and has consistently reported a high incidence of urolithiasis. ${ }^{14}$ Approximately $12 \%$ of the population suffers from urolithiasis once in their life-time and recurrence rate approaches $50 \%$ in coming years. ${ }^{15}$ Urolithiasis constitutes a major etiology of morbidity in adult and pediatric population in Pakistan. ${ }^{16}$

Though PCNL has reduced morbidity associated with open procedures, which were previously performed for large renal calculi, there still exists theoretical fear of surgical difficulty in previously operated cases due to scarring and distorted tissue anatomy. ${ }^{6,7}$ This fear has led to surgeons doing repeated open procedures in the past but due to newer advents of surgical instruments and radiological innovations; this notion is now a thing of the past.

During the past decade or so, several authors have shared their success stories of doing PCNL in previously operated patients, but few have also highlighted the operative obstacles faced. This dilemma has caused panic among surgeons to arrange surplus blood products during their cases of PCNL with such variable. Some surgeons have deemed PCNL in such patients to be less efficacious due to large residual stones, while others have advocated comparatively higher rates of access / procedure failure.

Sofikerim reported a retrospective case-control study on 89 patients who had underwent PCNL after having a previous open renal surgery. ${ }^{17}$ Like this study, this study also demonstrated comparable age, stone burden and laterality among both case and control groups. Both groups showed no difference in terms of operative time, postoperative analgesic doses, pain scores, intraoperative and postoperative complications, number of accesses or stone-free rate. We, on the other hand, did notcalculate pain scores and analgesic doses, but the rest was comparable.

Another review in 2006 by Shah consisted of 25 patients as cases and an equal number of controls. ${ }^{18}$ All cases studied were tubeless PCNL in the study, unlike the present study where both tubeless and with tube were examined. Shah HN also reported PCNL with such variable to be safe and effective in terms of stone clearance and complications.

In 2007, Kurtulus $^{19}$ performed a retrospective case-control study in Turkey, comprising of 328 patients among which 142 underwent PCNL secondary to some open renal procedure in the past, while remaining were controls for comparison. Baseline demographic details were similar in both groups and significant differences were not observed in terms of number of tract ( $8.5 \%$ vs. $10.2 \%$ ), operative time ( 2.3 vs. 2.2 hours), transfusion rate (540 vs. $495 \mathrm{~mL}$ ), hospitalisation time (4.4 vs. 4.2 days), complication rate ( $1.4 \%$ vs. $3 \%$ ) and residual stones ( $5 \%$ vs. $3 \%)$. With the difference of sample size, rest of parameters and results are comparable with this study. Access difficulty was faced by Kurtulus and was tackled by using high pressure balloon dilators for tract formation. ${ }^{19}$ Another more recent Turkish study by Yesil noticed a rare complication of vascular malformation during or after PCNL in previously operated kidneys. ${ }^{11}$ These vascular events were diagnosed on renal 
vascular angiography and ultimately required angioembolisation in few cases as well. The present authors did not check such complications.

Tugcu et al. also described similar results in their retrospective study performed in 2007 , but they took note of lengthy operative times in previously operated group due to scarring of tissue. ${ }^{20}$ In this study, the authors did not notice any significant difference in terms of operative time.

An Iranian study from 2007 by Amjadi implied slight variation in PCNL technique in previously operated patients. ${ }^{21}$ Among the 31 patients, half were assigned to the group in which Alken's serial dilators were used, while in the other group a 'one-shot' 27-Fr dilator was used for tract dilatation. Results implied no differences in safety and efficacy but there was significant reduction in radiation exposure in the 'one-shot' group. The present authors did not use 'one-shot' dilator study and only used the conventional Alkene's serial metallic dilators.

Two studies done on pediatric population with similar variables also mimicked the results of other authors. Aldaqadossi in 2014, and Onal in 2011 demonstrated the safety and efficacy to be comparable in PCNL patients with and without previous open surgery. ${ }^{12,13}$ There was concern regarding presence of retrorenal colon in previously operated cases which advocated use of preoperative CT scans. Pediatric PCNL cases not compared in this study.

Although PCNL is a minimally invasive procedure, butinthe presence of soft tissue scarring and tissue distortion due to previous surgery, renal access as well as tract dilatation can be challenging. The findings of this study proved that modern day techniques of PCNL are safe and effective even in scarred soft tissue. There is no objective reason to hold back the decision of performing PCNLin previously operated patients.

Prominent limitation of the study is lack of prospective trial. Larger sample size in a prospective setting would yield better representation of population in future trials. Although use of nephrostomy tube was statistically similar in both studies, but this small bias can also be removed in future studies by doing all cases tubeless. We did not use balloon dilators or 'one shot' dilators for the tract and hence the implications of such modalities are not well understood in our study. Vascular complications were not investigated by us which may impact on the outcome of such patients who have undergone previous surgery. Pediatric population may be included in our future studies to further investigate specific complications like retrorenal colon.

\section{CONCLUSION}

PCNL is a safe and effective procedure for sizable renal stones; even in previously operated kidneys, where there is significant fear of tissue scarring and distortion of normal calyceal anatomy. Modern instruments and innovated techniques have resulted in better surgical outcomes.

ETHICALAPPROVAL:

Ethical approval was provided by Ethical Committee of The
Kidney Centre, Dorab Patel Post Graduate Training \& Research Centre with (Reference \# 76-URO-052019), dated May 2019.

\section{PATIENTS' CONSENT:}

A detailed informed consents were taken from all patients, explaining about the risks and benefits of the surgical procedure and also about the research proceedings along with confidentiality methods.

\section{CONFLICT OF INTEREST:}

The authors declared no conflict of interest.

\section{AUTHORS' CONTRIBUTION:}

SM, FY, AS: Surgical practices.

SM: Conception of study.

AS: Design, analysis or interpretation of data and manuscript writing.

FY, AS, SH, WH, SK: Data collection and processing.

AS, FY, SM: Literature search.

\section{REFERENCES}

1. Sorokin I, Mamoulakis C, Miyazawa K, Rodgers A, Talati J, Lotan Y. Epidemiology of stone disease across the world. World J Urol 2017; 35(9):1301-20.

2. Karakose A, Aydogdu O, Atesci YZ. Does the use of smaller amplatz sheath size reduce complication rates in percutaneous nephrolithotomy. Urol J 2014; 11(4):1752-56.

3. Fernstrom I, Johansson B. Percutaneous pyelolithotomy: A new extraction technique. Scand J Urol Nephrol 1976; 10(3):257-9.

4. Alken P, Hutschenreiter G, Gunther R. Percutaneous stone manipulation. J Urol 1981; 125(4):463-6.

5. Segura JW, Patterson DE, LeRoy AJ. Percutaneous removal of kidney stones: Preliminary report. Mayo Clin Proc 1981; 57(10):615-9.

6. Viville C. Percutaneous nephrolithotomy. Personal experience in 100 cases. J Urol (Paris) 1987; 93(5):253-8.

7. Jones DJ, Russell GL, Kellett MJ, Wickham JE. The changing practice of percutaneous stone surgery. Review of 1000 cases 1981-1988. BrJ Urol 1990; 66(1):1-5.

8. Gupta R, Gupta A, Singh G, Suri A, Mohan SK, Gupta CL. $\mathrm{PCNL}$ - a comparative study in nonoperated and in previously operated (open nephrolithotomy/pyelolithotomy) patients: A single-surgeon experience. Int Braz J Urol 2011; 37(6):739-44.

9. Lojanapiwat B. Previous open nephrolithotomy: Does it affect percutaneous nephrolithotomy techniques and out come. J Endour 2006; 20(1):17-20.

10. Reddy SV, Shaik AB. Outcome and complications of percutaneous nephrolithotomy as primary versus secondary procedure for renal calculi. Int Braz J Urol 2016; 42(2):262-9.

11. Yesil S, Ozturk U, Goktug HN, Tuygun C, Nalbant I, Imamoglu MA. Previous open renal surgery increased vascular complications in percutaneous nephrolithotomy (PCNL) compared with primary and secondary PCNL and extracorporeal shock wave lithotripsy patients: A retrospective study. Urologiainternationalis 2013; 91(3): 
$331-4$.

12. Aldaqadossi HA, Kotb Y, Mohi K. Efficacy and safety of percutaneous nephrolithotomy in children with previous renal stone operations. J Endourol 2015; 29(8):878-82.

13. Onal B, Gevher F, Argun B, Dogan C, Citgez S, Onder AU, Erozenci A. Does previous open nephrolithotomy affect the outcomes and complications of percutaneous nephrolithotomy in children. J Pediatric Urology 2014; 10(4): 730-6.

14. Rizvi SA, Naqvi SA, Hussain Z, Hashmi A, Hussain M, Zafar MN, et al. The management of stone disease. BJU Int 2002; 89(1):62-8.

15. Teichman JM. Clinical practice. Acute renal colic from ureteral calculus. N Engl J Med 2004; 350(7):684-93.

16. Hussain M, Rizvi SA, Askari H, Sultan G, Lal M, Ali B. Management of stone disease: 17 years experience of a stone clinic in a developing country. J Pak Med Assoc 2009; 59(12):843-6.

17. Sofikerim M, Demirci D, Gülmez I, Karacagil M. Does previous open nephrolithotomy affect the outcome of percutaneous nephrolithotomy. J Endouro 2007; 21(4): 401-3.

18. Shah HN, Mahajan AP, Hegde SS, Bansal M. Tubeless percutaneous nephrolithotomy in patients with previous ipsilateral open renal surgery: A feasibility study with review of literature. J Endouro 2008; 22(1):19-24.

19. Kurtulus FO, Fazlioglu A, Tandogdu Z, Aydin M, Karaca S, Cek M. Percutaneous nephrolithotomy: Primary patients versus patients with history of open renal surgery. J Endouro 2008; 22(12):2671-6.

20. Tugcu V, Su FE, Kalfazade N, Sahin S, Ozbay B, Tasci Al. Percutaneous nephrolithotomy (PCNL) in patients with previous open stone surgery. Int Uro Nephro 2008; 40(4): 881-4.

21. Amjadi M, Zolfaghari A, Elahian A, Tavoosi A. Percutaneous nephrolithotomy in patients with previous open nephrolithotomy: one-shot versus telescopic technique for tract dilatation. J Endour 2008; 22(3):423-6. 